\title{
Covid-19-a rehearsal to build a greener and healthier society
}

\author{
Maria Nilsson and colleagues argue that reducing the severe health risks from the climate crisis \\ requires political commitment and funding like that mobilised to limit the spread of SARS-CoV-2
}

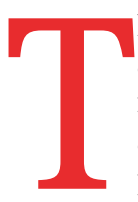
he covid-19 pandemic is hopefully a short-lived global crisis adding to existing global challenges arising from human behaviour, particularly the ongoing environmental and climate crises. Strict measures to control SARS-CoV-2, the virus that causes covid-19, were introduced rapidly in almost all countries, showing that the global community has the ability to prioritise health. International collaborations set immediate priorities to control SARS-CoV-2, including mobilising large financial resources. National decision makers proved ready to make far reaching decisions about finances and restrictive measures, which were largely accepted by citizens despite initially limited scientific evidence on effectiveness.

This response is in sharp contrast to the insufficient political willingness to act on the climate crisis, with global carbon emissions continuing to rise, despite longstanding international agreement to reduce them. Although the covid-19 pandemic is an acute global health threat that needs immediate action, climate change is likely to be a larger global public health threat in the medium and long run. ${ }^{1}$ If the world's greenhouse gas emissions and anthropogenic pollution

\section{KEY MESSAGES}

- Reducing greenhouse gas emissions is mandatory for human health and wellbeing in both the short and long term

- The investments and resources put into recovery plans for covid-19 must support transformation to renewable energy sources and green development

- The health implications will depend on the level of investment in transdisciplinary efforts to build health systems resilient to the prevailing environmental and climate crises

- Urgent global collaborative action in response to covid-19 must be replicated to improve planetary health and human wellbeing follow current trends, each additional unit of warming is projected to have primarily negative consequences for human and natural systems, including the upstream drivers of health. ${ }^{1}$ Reflections on the covid19 pandemic can inform and boost the development of the critical policies and action needed to overcome the existential environmental and climate change crises.

A healthy population is at the heart of most transformations needed to achieve global sustainable development. The guiding principle behind sustainable development is that humanity should meet the needs of today without compromising the ability of future generations to meet their needs. ${ }^{2}$ Numerous challenges must be overcome to reach the UN sustainable development goals, which set out the priorities and resources required to facilitate global cohesive action. ${ }^{3}$ These commitments for sustainability entail an uncompromising responsibility towards the world's young people, ${ }^{4}$ which will be even more important as countries recover from the effects of covid-19.

\section{Environmental crisis and health in covid-19 context}

Although human health improved substantially between 1950 and 2010, this gain was accompanied by global environmental degradation from climate change, loss of biodiversity, and reactive nitrogen and phosphorus being dumped on land and introduced into oceans and waterways. All of these threaten human health and the ecosystem services on which we depend. ${ }^{5}$ By tackling climate change, reducing the degradation of our natural environments, and building climate resilient health systems, we reduce the risk of emerging zoonotic diseases, one of many health threats. However, only half of the countries surveyed by the World Health Organization have national climate and health plans. ${ }^{6}$ The Carbon Disclosure Project reported that two thirds of cities surveyed are concerned that climate change will overwhelm their public health infrastructure. ${ }^{7}$

Climate change affects everybody, but some population groups are more vulnerable than others (box 1). The effect of climate change intersect with other societal changes-for example, population ageing and urbanisation. Vulnerabilities will vary in different places.

The velocity and extent of climate change challenges the global health gains made over recent decades. ${ }^{89}$ People who are vulnerable may be susceptible to relatively small changes in climatic conditions and their consequences. ${ }^{10}$ Two examples of health risks needing higher priority in climate change adaptation and mitigation that may be particularly relevant in the covid-19 context are heat related mortality and respiratory diseases associated with air pollution.

Many different population groups are at risk of exposure to increases in temperatures, more frequent heat waves, and air pollution (box 2). Small children may be particularly vulnerable to the effects of climate change as their bodies respond differently to harmful exposures, they lack control over the environment, and they depend on care and protection from adults. Children's behaviour may also expose them to risks. ${ }^{10}$ However, older adults have been exposed to air pollution from childhood and throughout their life, driven by fossil fuels and made worse by rising temperatures. Being exposed in childhood is a particular risk as the lungs are developing. It may lead to reduced lung function, and over time increase the risk of heart attacks and stroke. ${ }^{10}$

Box 1: Vulnerability to climate change ${ }^{8-10}$

- Particular individual sensitivity or inadequate operation of health and social systems increase vulnerabilities

- Among those most vulnerable are older people, children, pregnant women, migrants and other marginalised groups, people on low incomes, and those with pre-existing medical conditions that increase susceptibility

- The nature and type of hazard, the exposure, and the vulnerability of individuals determines the magnitude of health outcomes 
Box 2: Hazards of air pollution ${ }^{11-13}$

- WHO estimates that more than $90 \%$ of the world's population breathes polluted air, with low and middle income countries bearing the heaviest burden

- Air pollution alone kills around 7 million people a year, including about 600000 children aged under 5 years

- More than $40 \%$ of the world's population is exposed to high levels of household air pollution, mainly through cooking using polluting technologies and fuels

- Roughly two thirds of all deaths from outdoor air pollution result from fossil fuel combustion

In the context of covid-19, health challenges of already existing environmental and climatic change means a converging risk for older people, increasing the risk of morbidity and mortality due to cardiovascular and respiratory disease. The increased susceptibility may be explained by a lower reserve capacity physiologically, an immune system with a slower response, and a slower metabolism. Increased vulnerability may be related to poorer physical health, immobility, being in hospitals and nursing homes, and some commonly used medications. ${ }^{10}$

Potential underestimation of health risks related to heat means many more people are likely to be affected. ${ }^{10}$ The Lancet Countdown report on climate change and health reported that heatwave exposure among older people was at a record high in 2019. ${ }^{7}$ With prevailing policies, the world is projected to be up to $4^{\circ} \mathrm{C}$ warmer than in pre-industrial times by the end of the century, ${ }^{14}$ increasing the risks to health in such a way that they are difficult to predict.

Environmental degradation also has a more direct connection to covid-19. Most recent emerging infectious diseases-and all those responsible for recent pandemics, including HIV/AIDS, SARS, and Ebolahave jumped from wildlife to humans, and the evidence suggests that covid-19 has done the same. ${ }^{15}$ The conversion of natural habitats to human influenced ecosystems is recognised to increase the risk of new zoonotic disease in humans. ${ }^{16}$ More generally, ongoing human damage to the natural environment creates a global commons challenge: the total damage is no individual's problem but each individual contributes. There seems to be an appalling lack of understanding of the systemic risks being created in the longer term.
Climate and other environmental changes are consequences of past development pathways. Five years ago, when publishing the planetary boundary framework, ${ }^{17}$ Steffen and colleagues set out a safe operating space for humanity, stressing the need for a new model for continued development of human societies that maintains a resilient and sustainable earth system. If such a model is accompanied by changes in ecosystems and socioeconomic pathways, it may allow us to identify interactions that could substantially alter the burden of climate sensitive health outcomes, burdens for which health systems will have to be prepared.

The development choices made today will affect how the future looks. ${ }^{18} 19$ Covid-19 is an opportunity to reflect on pathways for moving forward to be better prepared for the next pandemic and build the resilience needed to be able to make a real difference for current and future generations. In healthcare, there is a willingness and readiness to take large and rapid steps to cure acute illness. But there is less willingness for the slower work of preventing illness, even when it is supported by robust evidence and the human and economic benefits would be much greater over both the short and long term. This is illustrated by the slow progress in efforts to control the epidemic of tobacco related disease (box 3).

\section{Natural experiment}

The covid-19 pandemic can be viewed as a natural experiment, showing that social change is possible with rapid cohesive international action, priority setting, and mobilisation of financial resources. Government lockdown policies to prevent the spread of covid-19 reduced travel, industrial production, and energy generation, which in turn decreased the greenhouse gas emissions that drive climate change and the presence of air pollutants. In April 2020, daily global $\mathrm{CO}_{2}$ emissions were $17 \%$ below the mean level in 2019, although levels rose again once restrictions were released. ${ }^{22}$ A recent estimate from the Global Carbon project suggested a 7\% fall in global $\mathrm{CO}_{2}$ emission from fossil fuel and industry for 2020. ${ }^{23}$ Despite this, Earth overshoot day-the date when nature's budget for the year is exhausted by humanity-was reported on 22 August 2020. ${ }^{24}$

After the global financial crisis in 200809, $\mathrm{CO}_{2}$ emissions rapidly rebounded, mainly from large emission growth in emerging economies, a rapid return
Box 3: Slow pace of prevention

- The lower interest in preventing future disease is not new. The association between tobacco use, severe disease, and premature death was first shown in the 1950s, but it was more than 50 years later that the global Framework Convention of Tobacco Control was developed, accepted, and ratified by WHO member states. The price of this delay was high-costing the lives of 100 million people. $^{20}$

- A lesson from tobacco control is the importance of protecting policy development from vested interest. The use of junk science and strategies to delay regulations and legislation has hampered national and global governance on climate change. ${ }^{21}$

- There is an obvious parallel here between the determination to prevent, handle, and treat covid-19 in the short term and the lack of commitment to decrease environmental and climate degradation and change, which is introducing more severe, major risks in the medium to long term.

to earlier levels of emission growth in developed economies, and an increase in fossil fuel carbon intensity. ${ }^{25}$ The global community should learn from this and design covid-19 recovery plans that protect vulnerable groups, mitigate climate change, focus on meeting temperature targets set in the Paris agreement, reduce air pollution, increase the resilience of health systems, and strengthen opportunities for green development. ${ }^{26}$

With regard to climate change, solid evidence is available to guide a planned social change with "green" innovations and use of green technology as part of economic recovery. An immediate increase in transport and travel can be expected after the pandemic, but this needs to be based on energy sources that do not contribute to accelerated climate change. This will not happen without better public policy. Global subsidies for fossil fuel consumption increased in 2016-18 by $50 \%,{ }^{27}$ wasting taxpayers' money and driving up air pollution and carbon emissions. A substantial change can be achieved by governments switching subsidies to support the consumption and development of green energy and technology.

During the covid-19 pandemic researchers from many disciplines quickly joined forces to build knowledge and 
find solutions. Scientific journals from a wide range of disciplines have given high priority to publishing articles related to covid-19. A similar combination of forces will be important to deal with future global challenges.

\section{Critical global health leadership and action at all levels}

Global health challenges require global leadership in which nations exchange information and strengthen cooperation. The covid-19 pandemic has once again shown the importance and need for global governance in meeting health challenges.

WHO has had a vital role in the covid19 pandemic. The organisation also had an important role in the eradication of wild polio from the African continent in 2020 , which is one of the largest public health successes since the eradication of smallpox. WHO now needs the support of member states to strengthen its ability to deal with future pandemics and health crises, giving it a broader mandate in collaboration with other UN environmental and development agencies. WHO's leadership in counteracting the environmental and climate crises is essential because, like covid-19, it requires short and long term policies, monitoring systems, and coordinated responses from national governments, the business sector, and the society at large.

The International Monetary Fund (IMF) has also had a key role during the pandemic, supporting financial order in member countries. Raising funds has not been the problem. Governments around the world in a few months deployed around $\$ 10$ tn to respond to the pandemic. ${ }^{28}$ They now have to invest continued funding wisely, putting green solutions at the forefront. The World Bank will also be important in supporting postpandemic economic development and social progress in low and middle income countries. International solidarity, global collaboration, and global governance through our UN, development, nongovernmental, and other organisations will be essential. Weak international partnerships reduce confidence and trust, resulting in fewer solutions and making it unlikely that the sustainable development goals will be achieved.

Climate change will affect the ability of health systems to function effectively, particularly when climate extremes are combined with existing and emerging health challenges, including outbreaks of infectious disease. Covid-19 has highlighted weaknesses in health systems and put a spotlight on inequities that have long persisted but received insufficient attention. Without prompt and effective climate change action, taking vulnerabilities and inequities into consideration, the problems are projected to worsen considerably. ${ }^{810}$

Throughout the pandemic, national decision makers have proved willing to make decisions with far reaching consequences. We now have to make use of this crisis and implement actions to protect people and the planet. The commitments for sustainable development are a responsibility for decision makers at all levels. Action now will improve the health of current and future generations.

Contributors and sources: MN is a public health researcher with focus on climate change and health. $\mathrm{KLE}$ is an epidemiologist researching the intersection of population health and climate variability and change. DCL heads the climate change and health programme at the World Health Organization. BK is an environmental epidemiologist, deputy director in charge of research programs of Côte d'Ivoire. PF is a physician and public health researcher with focus on adolescent health. All authors contributed to the conceptual ideas and design of the paper and approved the final version that builds on previous scientific evidence. MN wrote the full draft of the manuscript and incorporated comments from all authors. MN is the guarantor.

Competing interests: We have read and understood BMJ policy on declaration of interests and have no relevant interests to declare.

Provenance and peer review: Commissioned; externally peer reviewed.

This article is part of a collection launched at the Prince Mahidol Awards Conference (PMAC) in January 2021. Funding for the articles, including open access fees, was provided by PMAC. The BMJ commissioned, peer reviewed, edited, and made the decision to publish these articles. David Harper and an expert panel that included PMAC advised on commissioning for the collection. Rachael Hinton and Kamran Abbasi were the lead editors for The BMJ.

Maria Nilsson, professor of public health

Kristie L Ebi, professor of global health ${ }^{2}$

Diarmid Campbell-Lendrum, head of climate change and health unit ${ }^{3}$

Brama Kone, associate professor of environmental epidemiology ${ }^{4,5}$

Peter Friberg, professor of global health ${ }^{6,7}$

${ }^{1}$ Department of Epidemiology and Global Health, Umeå University, Umeå, Sweden

${ }^{2}$ Center for Health and the Global Environment, University of Washington, Seattle, WA, US

${ }^{3}$ Department of Environment, Climate Change and Health, World Health Organization, Geneva, Switzerland

${ }^{4}$ Department of Environment and Health, Swiss Centre for Scientific Research, Côte d'Ivoire

${ }^{5}$ Institute of Agropastoral Management, University Peleforo Gon Coulibaly, Korhogo, Côte d'Ivoire

${ }^{6}$ Department of Public Health and Community Medicine, Sahlgrenska Academy, Gothenburg University, Gothenburg, Sweden
'Swedish Institute for Global Health Transformation at the Royal Swedish Academy of Sciences, Stockholm, Sweden

Correspondence to: M Nilsson

maria.nilsson@umu.se

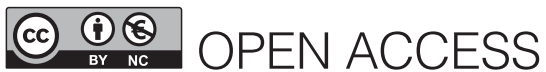

This is an Open Access article distributed in accordance with the Creative Commons Attribution Non Commercial (CC BY-NC 4.0) license, which permits others to distribute, remix, adapt, build upon this work non-commercially, and license their derivative works on different terms, provided the original work is properly cited and the use is non-commercial. See: http://creativecommons.org/ licenses/by-nc/4.0/.

\section{Check for updates}

1 IPCC. 2018: Global Warming of $1.5^{\circ} \mathrm{C}$. An IPCC special report on the impacts of global warming of $1.5^{\circ} \mathrm{C}$ above pre-industrial levels and related global greenhouse gas emission pathways, in the context of strengthening the global response to the threat of climate change, sustainable development, and efforts to eradicate poverty. 2019. https://www. ipcc.ch/site/assets/uploads/sites/2/2019/06/ SR15_Full_Report_High_Res.pdf

2 Brundtland G. Report of the World Commission on Environment and Development: our common future. United Nations General Assembly document A/42/427, UN, 1987

3 United Nations. Transforming our world: the 2030 agenda for sustainable development. 2020. https://sustainabledevelopment.un.org/content/ documents $/ 21252030 \% 20$ Agenda\%20for $\% 20$ Sustainable\%20Development\%20web.pdf

4 Clark H, Coll-Seck AM, Banerjee A, et al. A future for the world's children? A WHO-UNICEFLancet Commission. Lancet 2020;395:605-58. doi:10.1016/S0140-6736(19)32540-1

5 World Health Organization. Our planet, our health, our future. Human health and the Rio conventions: biological diversity, climate change and desertification. 2012. https://www.who.int/globalchange/ publications/reports/health rioconventions.pdf?ua $=1$

6 WHO. WHO health and climate change survey report: tracking global progress. World Health Organization, 2019

7 Watts N, Amann M, Arnell N, et al. The 2020 report of The Lancet Countdown on health and climate change: responding to converging crises. Lancet 2020;397:129-70.

8 Watts N, Adger WN, Agnolucci P, et al. Health and climate change: policy responses to protect public health. Lancet 2015;386:1861-914. doi:10.1016/ S0140-6736(15)60854-6.

9 Smith KR, Woodward A, Campbell-Lendrum D, et al. Human health: impacts, adaptation, and co-benefits. In: Climate change 2014: impacts, adaptation, and vulnerability. Part A: global and sectoral aspects. contribution of working group II to the fifth assessment report of the Intergovernmental Panel on Climate Change. Cambridge University Press, 2014: 709-54.

10 EASAC. The imperative of climate action to protect human health in Europe-opportunities for adaptation to reduce the impacts and for mitigation to capitalise on the benefits of de "isation. EASAC policy report 38. 2019. https://easac.eu/ publications/details/the-imperative-of-climateaction-to-protect-human-health-in-europe/

11 WHO. 9 out of 10 people worldwide breathe polluted air, but more countries are taking action. Press release, 2 May 2018. https://www.who.int/ news-room/detail/02-05-2018-9-out-of-10-peopleworldwide-breathe-polluted-air-but-more-countriesare-taking-action 
12 Lelieveld J, Klingmüller K, Pozzer A, Burnett RT, Haines A, Ramanathan V. Effects of fossil fuel and total anthropogenic emission removal on public health and climate. Proc Natl Acad Sci U S A 2019;116:7192-7. doi:10.1073/pnas.1819989116

13 Unicef. Clear the air for children. 2016. https://www. unicef.org/publications/files/UNICEF_Clear_the_Air_ for_Children_30_Oct_2016.pdf

14 Climate Action Tracker. Global update: Paris agreement turning point. 2020. https:// climateactiontracker.org/publications/global-updateparis-agreement-turning-point/

15 WHO. WHO manifesto for a healthy and green recovery from covid-19. 2020. https://www.who.int/ docs/default-source/climate-change/who-manifestofor-a-healthy-and-green-post-covid-recovery.pdf

16 Myers SS, Gaffikin L, Golden CD, et al. Human health impacts of ecosystem alteration. Proc Natl Acad Sci U SA 2013;110:18753-60. doi:10.1073/ pnas.1218656110

17 Steffen W, Richardson K, Rockström J, et al. Sustainability. Planetary boundaries: guiding human development on a changing planet. Science 2015;347:1259855. doi:10.1126/science.1259855
18 Sellers S, Ebi KL. Climate change and health under the shared socioeconomic pathway framework. Int Environ Res Public Health 2017;15:3. doi:10.3390/ ijerph15010003

19 Sellers S. Cause of death variation under the shared socioeconomic pathways. Clim Change 2020;1-19. doi:10.1007/s10584-020-02824-0.

20 Nilsson M, Beaglehole R, Sauerborn R. Climate policy: lessons from tobacco control. Lancet 2009;374:1955-6. doi:10.1016/S01406736(09)61959-0

21 Oreskes N, Conway EM. Defeating the merchants of doubt. Nature 2010;465:686-7. doi:10.1038/465686a

22 Le Quéré C, Jackson RB, Jones MW, et al. Temporary reduction in daily global $\mathrm{CO} 2$ emissions during the COVID-19 forced confinement. Nat Clim Chang 2020;10:647-53. doi:10.1038/s41558020-0797-x.

23 Global Carbon Project. Coronavirus causes 'record fall' in fossil-fuel emissions in 2020.11 Dec 2020 https://www.carbonbrief.org/global-carbon-projectcoronavirus-causes-record-fall-in-fossil-fuelemissions-in-2020
24 Global Footprint Network. Earth overshoot day. https://www.footprintnetwork.org/our-work/earthovershoot-day/\#: :text=In\%202020\%2C\%20 Earth\%200vershoot\%20Day,carbon\%20 dioxide\%20in\%20the\%20atmosphere

25 Peters GP, Marland G, Le Quéré C, Boden T, Canadell J, Raupach M. Rapid growth in $\mathrm{CO}_{2}$ emissions after the 2008-2009 global financial crisis. Nat Clim Chang 2011;2:2-4. doi:10.1038/nclimate1332.

26 WHO. WHO Manifesto for a healthy recovery from covid-19. 26 May 2020. https://www.who.int/newsroom/feature-stories/detail/who-manifesto-for-ahealthy-recovery-from-covid-19

27 Watts N, Amann M, Arnell N, et al. The 2019 report of The Lancet Countdown on health and climate change: ensuring that the health of a child born today is not defined by a changing climate. Lancet 2019;394:1836 78. doi:10.1016/S0140-6736(19)32596-6

28 International Monetary Fund. IMF blog, 20 May 2020. https://blogs.imf.org/2020/05/20/trackingthe-9-trillion-global-fiscal-support-to-fight-covid-19/

Cite this as: $B M / 2021: 372: \mathrm{n} 127$

http://dx.doi.org/10.1136/bmj.n127 